\title{
Knowledge of blood loss at delivery among postpartum patients
}

\author{
Michaela K Farber ${ }^{\text {Corresp., }}{ }^{1}$, Claire M Miller ${ }^{2}$, Bharathi Ramachandran ${ }^{2}$, Priya Hegde ${ }^{2}$, Kulsum Akbar $^{2}$, \\ Lawrence Tim Goodnough ${ }^{3}$, Alexander J Butwick ${ }^{2}$ \\ ${ }^{1}$ Department of Anesthesiology, Brigham and Women's Hospital, Harvard Medical School, Boston \\ 2 Department of Anesthesiology, Perioperative and Pain Medicine, Stanford University School of Medicine, Stanford, California, United States \\ 3 Departments of Pathology and Medicine, Stanford University School of Medicine, Stanford, California, United States \\ Corresponding Author: Michaela K Farber \\ Email address: mkfarber@partners.org
}

Background: Postpartum hemorrhage (PPH) is a leading cause of obstetric morbidity. There is limited understanding of patients' knowledge about blood loss at delivery, PPH, and PPH-related morbidities, including transfusion and anemia.

Methods: We surveyed 100 healthy postpartum patients who underwent vaginal or cesarean delivery about blood loss, and whether they received information about transfusion and peripartum hemoglobin $\mathrm{Hb}$ testing. Responses were compared between women undergoing vaginal delivery vs. cesarean delivery; $\mathrm{P}<0.05$ considered as statistically significant.

Results: In our cohort, 49 women underwent vaginal delivery and 51 women underwent cesarean delivery. Only 29 (29\%) of women provided blood loss estimates for their delivery. Women who underwent cesarean delivery were more likely to receive clear information about transfusion therapy than those undergoing vaginal delivery $(43.1 \%$ vs. $20.4 \%$ respectively; $P=0.04)$. Women who underwent vaginal delivery were more likely to receive results of postpartum $\mathrm{Hb}$ tests compared to those undergoing cesarean delivery (49\% vs. $29.4 \%$; $P=0.02$ ).

Conclusion: Our findings suggest that women are poorly informed about the magnitude of blood loss at delivery. Hematologic information given to patients varies according to mode of delivery. Further research is needed to better understand the clinical implications of patients' knowledge gaps about PPH, transfusion and postpartum anemia. 


\section{Title Page}

2 Title: Knowledge of Blood Loss at Delivery Among Postpartum Patients

1. Michaela K. Farber, MD MS

Department: Anesthesiology, Perioperative, and Pain Medicine

Affiliation: Harvard Medical School, Brigham and Women's Hospital

Email: mkfarber@partners.org

2. Claire M. Miller, BA

Department: Anesthesiology, Perioperative, and Pain Medicine

Affiliation: Stanford University School of Medicine

Email: clairemm@stanford.edu

3. Bharathi Ramachandran, BS

Department: Anesthesiology, Perioperative, and Pain Medicine

Affiliation: Stanford University School of Medicine

Email: rbharathi722@gmail.com

Department: Anesthesiology, Perioperative, and Pain Medicine 


\section{Kulsum Akbar, MD}

Department: Anesthesiology, Perioperative, and Pain Medicine Affiliation: Stanford University School of Medicine

Email: kulsum.akbar81@gmail.com

\section{Lawrence T. Goodnough, MD}

Departments: Pathology and Medicine

Affiliation: Stanford University School of Medicine

Email: LTGoodno@stanford.edu

\section{Alexander J. Butwick, MD}

Department: Anesthesiology, Perioperative, and Pain Medicine

Affiliation: Stanford University School of Medicine

Email: ajbut@stanford.edu

(1)

\section{Corresponding Author:}

1 Dr. Michaela K. Farber; Department of Anesthesiology, Perioperative, and Pain Medicine;

Brigham and Women's Hospital, Harvard Medical School; 75 Francis Street; Boston, MA 02115; USA.

Phone: (617) 759-1609

Fax (617) 264-6841

Email: mkfarber@partners.org 
49 Abstract:

50 Background: Postpartum hemorrhage (PPH) is a leading cause of obstetric morbidity. There is

51 limited understanding of patients' knowledge about blood loss at delivery, PPH, and PPH-related 52 morbidities, including transfusion and anemia.

53 Methods: We surveyed 100 healthy postpartum patients who underwent vaginal or cesarean 54 delivery about blood loss, and whether they received information about transfusion and 55 peripartum hemoglobin $(\mathrm{Hb})$ testing. Responses were compared between women undergoing 56 vaginal delivery vs. cesarean delivery; $\mathrm{P}<0.05$ considered as statistically significant.

57 Results: In our cohort, 49 women underwent vaginal delivery and 51 women underwent 58 cesarean delivery. Only 29 (29\%) of women provided blood loss estimates for their delivery. 59 Women who underwent cesarean delivery were more likely to receive clear information about 60 transfusion therapy than those undergoing vaginal delivery (43.1\% vs. $20.4 \%$ respectively; $\mathrm{P}=0.04)$. Women who underwent vaginal delivery were more likely to receive results of

62 postpartum $\mathrm{Hb}$ tests compared to those undergoing cesarean delivery (49\% vs. 29.4\%; $\mathrm{P}=0.02$ ).

63 Conclusion: Our findings suggest that women are poorly informed about the magnitude of blood 64 loss at delivery. Hematologic information given to patients varies according to mode of delivery. 65 Further research is needed to better understand the clinical implications of patients' knowledge gaps about PPH, transfusion and postpartum anemia.

67

68

69

Short title: Patient survey of blood loss at delivery 


\section{Introduction:}

73 In the United States, the rate of severe postpartum hemorrhage (PPH) has been steadily

74 increasing.(Callaghan et al. 2010; Kramer et al. 2013) In order to decrease the frequency of PPH, 75 clinical guidelines have been published to optimize PPH management practices.(ACOG 2006;

76 American Society of Anesthesiologists 2015; Main et al. 2015) Obstetric and anesthetic care

77 providers may also obtain updates about PPH management from literature review and other

78 educational forums, such as seminars and conferences. However, it is uncertain whether patients

79 receive information about $\mathrm{PPH}$ and $\mathrm{PPH}-$ related morbidities, such as transfusion and postpartum

80 anemia.

81 If patients are inadequately informed about $\mathrm{PPH}$, transfusion, and postpartum anemia,

82 this may have important clinical and health-related implications. Firstly, PPH is recognized as an

83 important cause of postpartum anemia. Women who develop postpartum anemia may be at risk

84 for anemia-related morbidities, including: postpartum depression, reduced cognition, and

85 impaired maternal-neonatal bonding.(Milman 2011) Secondly, patients who experience PPH

86 may not receive postpartum counseling. This may negatively impact on how patients cope with

87 the emotional trauma of experiencing major PPH.(Thompson et al. 2011b) Thirdly, patient-

88 centered care and shared decision-making about transfusion have been promoted in the

89 perioperative and medical literature.(Friedman et al. 2012; Vetter et al. 2014; Weiner et al. 2013)

90 These approaches have not been well described in the obstetric setting, therefore examining

91 patients' knowledge of anticipated and actual blood loss at delivery may help inform clinical

92 practice.

93 To evaluate patients' knowledge and perceptions of postpartum blood loss, we surveyed a

94 cohort of women who underwent vaginal delivery or cesarean delivery at a US tertiary obstetric 
95 center. We secondarily examined whether patients receive information from their care providers

96 about transfusion, and antepartum and postpartum $\mathrm{Hb}$ levels.

97

98

99

100

101

102

103

104

105

106

107

108

109

110

111

112

115

116

117

\section{Methods:}

This study was approved by Stanford University IRB, Stanford, CA (Protocol\#26391).

Using a convenience sample, we enrolled 100 healthy (ASA physical status 1 or 2) patients who underwent vaginal delivery or cesarean delivery at Lucile Packard Children's Hospital, a tertiary obstetric center in California, USA. During the postpartum hospitalization, postpartum patients were approached and written informed consent was obtained. We excluded women with psychological disorders or psychiatric disease.

For this study, we asked patients two sets of questions about blood loss. One set of questions assessed patients' baseline knowledge of normal blood loss following an uncomplicated vaginal or cesarean delivery. The second set of questions was related to the blood loss that occurred for their actual delivery (vaginal or cesarean). For each set of questions, a trained study investigator $(\mathrm{PH}, \mathrm{BR}, \mathrm{KA})$ surveyed patients using a written questionnaire and recorded patients' responses. Survey questions are presented in an online supplement (Supplement 1). The questionnaire also contained questions related to patients' socioeconomic status and educational background.

For the first set of questions, we asked patients to quantify volumes of blood loss for a normal, uncomplicated vaginal delivery and cesarean delivery. For the second set of questions, we asked patients to quantify the estimated blood loss for their actual delivery (hereafter referred to as $\mathrm{EBL}_{\text {patient }}$ ), and to indicate whether an obstetric care provider informed them of their EBL. 
118 For each patient's delivery hospitalization, we abstracted demographic, medical, obstetric and

119 laboratory data from the electronic medical record, including: total EBL for their delivery

120 (hereafter referred to as $\mathrm{EBL}_{\text {delivery }}$ ), the antenatal hemoglobin $(\mathrm{Hb})$ level most proximate to

121 delivery, the postpartum $\mathrm{Hb}$ level measured closest to the day of hospital discharge, and relevant

122 transfusion data.

123 For our secondary analysis, we asked directed questions related to transfusion and $\mathrm{Hb}$

124 testing. We assessed whether patients were given information, during the antenatal period, about

125 transfusion, and whether they would consent to a transfusion, if clinically indicated. We asked

126 patients whether they received information about their antenatal and postpartum Hb levels from

127 obstetric care providers.

128 Statistical Analyses:

129 Data are presented as mean (standard deviation), median [interquartile range], and number

130 (percentages), as appropriate. For continuous data, we assessed normal distributions using QQ

131 plots and the Kolmogorov-Smirnov test. We compared patient characteristics and survey

132 responses between women who underwent vaginal vs. cesarean delivery with a t test or Mann-

133 Whitney test for continuous data, and $\chi^{2}$ test or Fisher's exact test for categorical data. We

134 compared $\mathrm{EBL}_{\text {patient }}$ values to $\mathrm{EBL}_{\text {delivery }}$ values for women who underwent vaginal and cesarean

135 delivery respectively, using Wilcoxon signed rank sum test.

136 Using EBL data, we classified PPH using the following EBL thresholds: $\geq 500 \mathrm{ml}$ EBL

137 for vaginal delivery and $\geq 1000 \mathrm{ml} \mathrm{EBL}$ for cesarean delivery. We calculated sensitivity,

138 specificity, positive predictive value (PPV) and negative predictive value (NPV) to determine

139 whether PPH was accurately classified by patients' EBL estimates for their actual delivery. 
140 Statistical analysis was performed using STATA version 12 (Stata Corp., College Station, TX).

$141 \mathrm{P}<0.05$ was considered as statistically significant.

142

143 Results:

144 A total of 100 patients were recruited, of which 49 underwent vaginal delivery and 51 underwent

145 cesarean delivery. Demographic, socioeconomic, and obstetric characteristics for the full cohort

146 and for women stratified by mode of delivery are presented in Table 1 . In the full cohort, the

147 majority of women had private health insurance, were Caucasian or Asian, married, and had an

148 annual household income of at least \$50,000. Compared to women who underwent vaginal

149 delivery, women who underwent cesarean delivery were older, had a higher parity, were

150 delivered at a later gestational age, and were more likely to have undergone prior cesarean

151 delivery.

152 Data related to the first set of questions about blood loss for an uncomplicated vaginal or

153 cesarean delivery are presented in Table 2. Over two-thirds of patients did not provide estimates

154 for normal blood loss after an uncomplicated vaginal or cesarean delivery. Among those who

155 were willing to provide estimates, patients reported that the mean normal blood loss is higher

156 after an uncomplicated cesarean delivery compared with an uncomplicated vaginal delivery.

157 The median $[\mathrm{IQR}] \mathrm{EBL}_{\text {delivery }}$ values were significantly higher for women who underwent

158 cesarean delivery compared to vaginal delivery (730 [600-1000] ml vs. 250 [200-300] ml

159 respectively; $P<0.001)$. A total of 18 women experienced $\mathrm{PPH}$ : four of these women underwent

160 vaginal delivery, and 14 underwent cesarean delivery. Of note, no patients received transfusion.

161 Complete data on $\mathrm{EBL}_{\text {patient }}$ and $\mathrm{EBL}_{\text {delivery }}$ values were available for only 29 patients

162 (Figure 1). For those with complete data who underwent vaginal delivery ( $\mathrm{n}=16), \mathrm{EBL}_{\mathrm{patient}}$ 
163 values were significantly higher than $\mathrm{EBL}_{\text {delivery }}$ values (400 ml [300-578 ml] vs. 250 [200-300

$164 \mathrm{ml}$ ] respectively; $\mathrm{P}=0.02$ ). In contrast, for those with complete data who underwent cesarean

165 delivery ( $\mathrm{n}=13), \mathrm{EBL}_{\text {patient }}$ values were significantly lower than $\mathrm{EBL}_{\text {delivery }}$ values $(550 \mathrm{ml}$ [400-

$166800 \mathrm{ml}]$ vs. 750 [600-1000 ml]; $\mathrm{P}=0.02)$. For the 29 patients with complete $\mathrm{EBL}_{\text {patient }}$ and

167 EBL $_{\text {delivery }}$ data, we calculated sensitivity, specificity, PPV and NPV to determine whether PPH

168 was accurately classified according to $\mathrm{EBL}_{\text {patient }}$ values. The sensitivity was $60 \%(95 \%$

$169 \mathrm{CI}=14.7 \%-94.7 \%)$, specificity was $83.3 \%(95 \% \mathrm{CI}=62.6 \%-95.3 \%)$, PPV was $42.9 \%(95 \%$

$170 \mathrm{CI}=9.9 \%-81.6 \%)$, and NPV was $90.9 \%(95 \% \mathrm{CI}=70.8 \%-98.9 \%)$.

$171 \mathrm{Hb}$ levels were not measured before or after delivery for 11 women and 20 women,

172 respectively. Predelivery $\mathrm{Hb}$ levels were similar for those who underwent vaginal vs. cesarean

173 delivery: $12.4(1.4) \mathrm{g} / \mathrm{dl}$ vs. $12.3(0.9) \mathrm{g} / \mathrm{dl}$, respectively; $\mathrm{P}=0.8$. Similarly, no significant

174 difference was observed in the last $\mathrm{Hb}$ measured before hospital discharge between women who

175 underwent vaginal vs. cesarean delivery: $10.6(1.1) \mathrm{g} / \mathrm{dl}$ vs. 10.4 (1.0) g/dl, respectively; $\mathrm{P}=0.3$.

176 Data of patients' knowledge of transfusion and $\mathrm{Hb}$ levels are presented in Table 3.

177 Women who underwent cesarean delivery were more likely to have received clear and

178 understandable information about transfusion and were more likely to consent to transfusion

179 compared to women who had a vaginal delivery. With regard to Hb levels, patients who

180 underwent vaginal delivery were more likely to have known their $\mathrm{Hb}$ level before delivery

181 compared to those who underwent cesarean delivery. The proportion of patients who stated that

182 their postpartum $\mathrm{Hb}$ level was measured was similar among women who underwent vaginal vs

183 cesarean delivery ( $40.8 \%$ vs. $47 \%$ respectively; $\mathrm{P}=0.74)$. However, among women who stated

184 that their postpartum Hb level was measured, only $3(7 \%)$ were given the test result. 


\section{Discussion:}

187 Our study provides insight into obstetric patients' perceptions and knowledge of blood loss at 188 delivery, transfusion, and laboratory testing for anemia. Over two-thirds of patients did not 189 provide blood loss estimates for their delivery. Additionally, less than $50 \%$ of patients indicated 190 that they received information about their pre- or post-delivery Hb levels. Lastly, the quality of

191 transmitted information about transfusion and patients' consent for transfusion varied according 192 to mode of delivery. Based on our findings, a low proportion of women who deliver at a US 193 tertiary obstetric center receive information about the clinical implications of peripartum blood 194 loss, transfusion, and $\mathrm{Hb}$ testing before and after delivery.

195 It is unclear why the majority of women in our study did not provide blood loss

$196\left(\mathrm{EBL}_{\text {patient }}\right)$ values. We speculate that the reason is that many patients did not receive blood loss 197 information after delivery. Those who did provide blood loss estimates for their delivery were 198 relatively poor at correctly classifying $\mathrm{PPH}$ (sensitivity $=60 \%$; $\mathrm{PPV}=42.9 \%$ ). One possible 199 explanation for these findings is that, within this subcohort [of women who gave blood loss 200 estimates], women may not have been informed about the magnitude of their peripartum blood 201 loss. In addition, it is also possible that some women correctly estimated their blood loss without 202 receiving any EBL information from their obstetric care provider.

Although it is unclear whether patients who undergo uncomplicated deliveries need to be 204 notified of their EBL or postpartum $\mathrm{Hb}$ levels, patients who experience PPH may benefit from receiving more detailed information about these indices. Thompson et al. reported that patients who experience PPH express interest in receiving information related to their delivery, and may benefit from counseling, psychological support, and assistance with physical recovery.(Thompson et al. 2011a) Furthermore, physicians' estimate of blood loss can often be 
209 lower than the actual volume of blood lost at delivery.(Lilley et al. 2015; Toledo et al. 2007)

210 Therefore, if blood loss is underestimated for women with PPH, then these women may develop

211 anemia that goes undetected after delivery. To improve patient awareness of postpartum anemia,

212 there may be benefit in providing patients with information sheets which contain advice about

213 seeking medical review if they experience anemia-related symptoms (e.g., low mood, fatigue,

214 poor cognition).

215 In our study, patients who underwent cesarean delivery were more likely to receive

216 information about transfusion compared to those who underwent vaginal delivery. Obstetricians

217 may be more likely to discuss the need for transfusion with patients who undergo cesarean

218 delivery, as these women are at greater risk of PPH than those undergoing vaginal

219 delivery.(Bateman et al. 2010) Surprisingly, 20\% of women who underwent vaginal delivery

220 reported that they would not provide consent for a blood transfusion should the obstetrician deem

221 it necessary. This finding is somewhat concerning as prompt transfusion therapy may be needed

222 for women who experience severe PPH or postpartum anemia. Misconceptions about transfusion

223 risk may explain why patients object to transfusion therapy. These misconceptions may be

224 influenced by sociodemographic factors. For example, in a survey of patients' perceptions of

225 transfusion by Vetter et al., patients with a high school education or less expressed increased

226 concern about the risk of allergic reaction, dyspnea, human immunodeficiency virus

227 transmission, and medical error.(Vetter et al. 2014) In a different survey examining patients'

228 beliefs about transfusion, Finucane et al. observed that patients' decision to receive transfusion

229 may vary according to patient's sex, race/ethnicity, and prior educational history.(Finucane et al.

230 2000) In light of these findings, counseling during the antenatal period may help allay the

231 concerns and fears of patients who express a desire to avoid transfusion. 
Antenatal and postpartum anemia can affect up to $52 \%$ and $24 \%$ women

233 respectively.(Milman 2008; Milman 2011) However, in our study, despite the majority of

234 women having $\mathrm{Hb}$ levels measured before and after delivery, fewer than $50 \%$ indicated that they

235 received any information regarding the results of these tests. Hb testing was less common for

236 women who underwent vaginal delivery. To determine optimal screening practices, more

237 population-based studies are needed to assess the frequency of postpartum anemia.

There are some limitations to our study. Our cohort size was relatively small, with

patients recruited at a single, tertiary obstetric center. In addition, the majority of women had private insurance, were well educated, were Caucasian or Asian, and had an annual income of $>$ $\$ 50,000$. Therefore, the specific characteristics of our study population limit the generalizability

242 of our findings. Further investigations are needed to assess knowledge and perceptions of blood

243 loss among women from other sociodemographic backgrounds, including those without English

244 proficiency. Our study cohort comprised healthy women who underwent uncomplicated vaginal 245 or cesarean delivery. We did not collect information on indications for cesarean delivery or, if 246 given, the timing of antenatal counseling. It is possible that the presence of select risk factors for 247 PPH may influence if and when physicians inform patients about peripartum blood loss, anemia 248 or transfusion. For example, the likelihood of antenatal counseling may be greater for women 249 with antenatal conditions linked to severe $\mathrm{PPH}$, such as placenta previa or accreta, than for 250 women with uncomplicated pregnancies. Recall bias is a possibility as we performed our survey 251 after delivery. Patients' responses may have differed if our survey had been prospectively 252 performed. Lastly, this was a convenience sample, therefore the proportion of patients who 253 underwent cesarean delivery in our study cohort (51\%) is not representative of the rate of 254 cesarean delivery at LPCH (approximately 31\%). In addition, in our study cohort, the proportion 
255 of women who experienced PPH (18\%) is higher than reported in the literature.(Bateman et al.

256 2010) As our study was exploratory in nature, further studies are needed to validate our findings

257 using populations are more representative of a typical delivery population.

258 In conclusion, our findings suggest that obstetric patients receive limited information

259 about peripartum blood loss, transfusion and peripartum $\mathrm{Hb}$ testing. In addition, patients'

260 understanding of transfusion and postpartum $\mathrm{Hb}$ testing may vary according to mode of delivery.

261 Future qualitative studies are needed to examine whether better patient-provider communication

262 improves patients' understanding and awareness about the clinical implications of $\mathrm{PPH}$, anemia,

263 and transfusion therapy, and to examine alternative ways to disseminate relevant information to 264 patients.

265

266 Acknowledgements: The authors would like to thank Flavya Esteves who assisted with data 267 collection for this study. 


\section{References:}

271 ACOG. 2006. Postpartum hemorrhage. Practice Bulletin No. 76. American College of Obstetricians and Gynecologists. Obstet Gynecol 108:1039-1047.

273 American Society of Anesthesiologists. 2015. Practice guidelines for perioperative blood management: an updated report by the American Society of Anesthesiologists task force on perioperative blood management*. Anesthesiology 122:241-275.

Bateman BT, Berman MF, Riley LE, Leffert LR. 2010. The epidemiology of postpartum hemorrhage in a large, nationwide sample of deliveries. Anesth Analg 110:1368-1373.

278

279

280

281

282

283

284

285

286

287

288

289

290

Callaghan WM, Kuklina EV, Berg CJ. 2010. Trends in postpartum hemorrhage: United States, 1994-2006. Am J Obstet Gynecol 202:353 e351-356.

Finucane ML, Slovic P, Mertz CK. 2000. Public perception of the risk of blood transfusion. Transfusion 40:1017-1022.

Friedman M, Arja W, Batra R, Daniel S, Hoehn D, Paniz AM, Selegean S, Slova D, Srivastava S, Vergara N. 2012. Informed consent for blood transfusion: what do medicine residents tell? What do patients understand? Am J Clin Pathol 138:559-565.

Kramer MS, Berg C, Abenhaim H, Dahhou M, Rouleau J, Mehrabadi A, Joseph KS. 2013. Incidence, risk factors, and temporal trends in severe postpartum hemorrhage. Am J Obstet Gynecol 209:449 e441-447.

Lilley G, Burkett-St-Laurent D, Precious E, Bruynseels D, Kaye A, Sanders J, Alikhan R, Collins PW, Hall JE, Collis RE. 2015. Measurement of blood loss during postpartum haemorrhage. Int J Obstet Anesth 24:8-14. 
291 Main EK, Goffman D, Scavone BM, Low LK, Bingham D, Fontaine PL, Gorlin JB, Lagrew DC,

292 Levy BS. 2015. National Partnership for Maternal Safety: Consensus Bundle on Obstetric 293 Hemorrhage. Obstet Gynecol 126:155-162.

294 Milman N. 2008. Prepartum anaemia: prevention and treatment. Ann Hematol 87:949-959.

295 Milman N. 2011. Postpartum anemia I: definition, prevalence, causes, and consequences. Ann Hematol 90:1247-1253.

297 Thompson JF, Ford JB, Raynes-Greenow CH, Roberts CL, Ellwood DA. 2011a. Women's experiences of care and their concerns and needs following a significant primary postpartum hemorrhage. Birth 38:327-335.

Thompson JF, Roberts CL, Ellwood DA. 2011b. Emotional and physical health outcomes after significant primary post-partum haemorrhage (PPH): a multicentre cohort study. Aust NZ J Obstet Gynaecol 51:365-371.

Toledo P, McCarthy RJ, Hewlett BJ, Fitzgerald PC, Wong CA. 2007. The accuracy of blood loss 304 estimation after simulated vaginal delivery. Anesth Analg 105:1736-1740.

Vetter TR, Adhami LF, Porterfield JR, Jr., Marques MB. 2014. Perceptions about blood transfusion: a survey of surgical patients and their anesthesiologists and surgeons. Anesth Analg 118:1301-1308.

Weiner SJ, Schwartz A, Sharma G, Binns-Calvey A, Ashley N, Kelly B, Dayal A, Patel S, 309 Weaver FM, Harris I. 2013. Patient-centered decision making and health care outcomes: an observational study. Ann Intern Med 158:573-579. 
313 Figure 1. Recorded blood losses and patients' estimates of blood loss according to mode of

\section{4 delivery.}

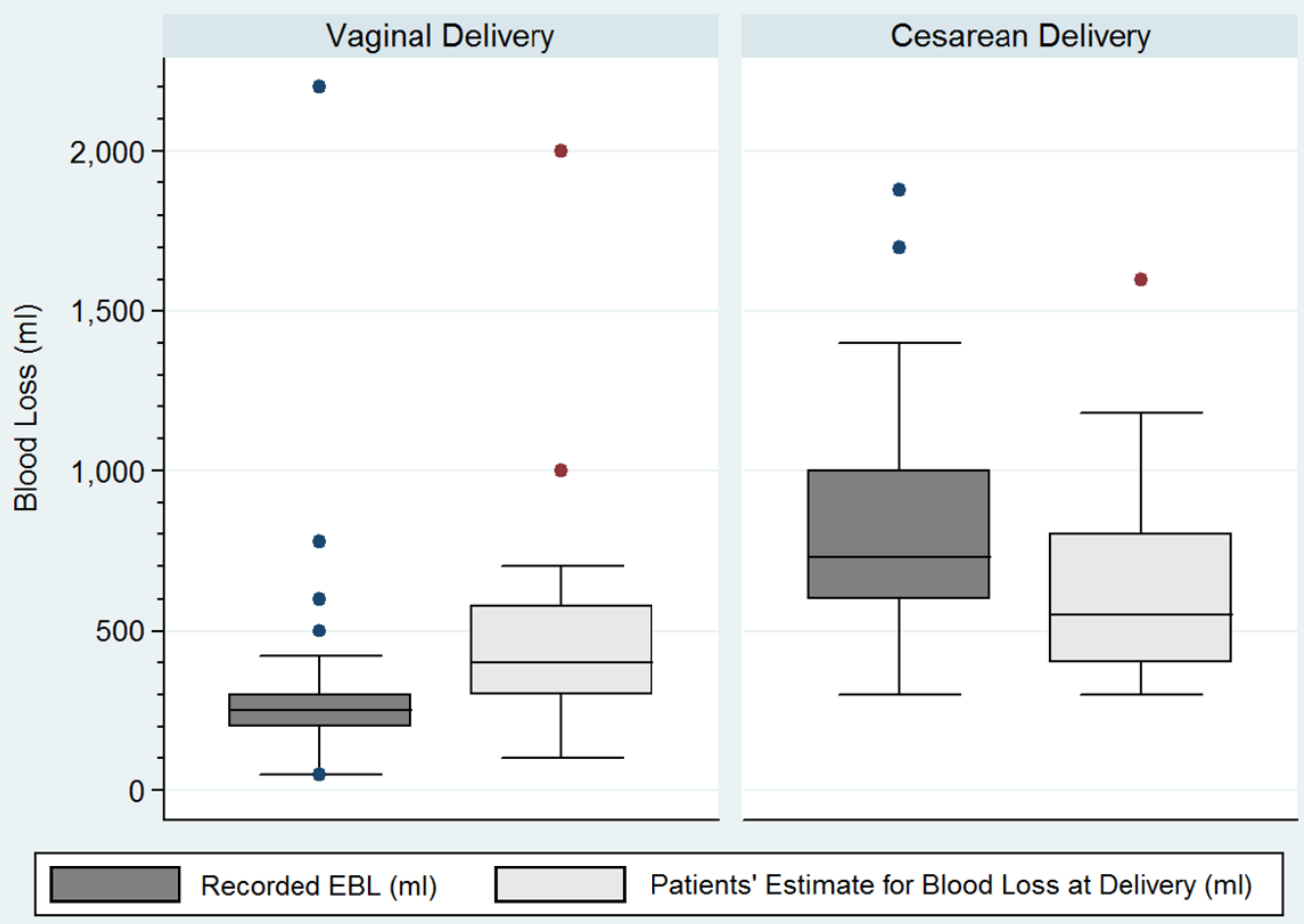

$316 \quad \mathrm{EBL}=$ estimated blood loss

317 Median (interquartile range) in blood loss. Horizontal line denotes median values, box borders

318 refer to interquartile range, whiskers indicate range of values, circles indicate outliers $(>1.5$ times

319 the interquartile range).

320 The recorded blood loss was not documented in the medical records of 4 patients who underwent

321 vaginal delivery and 1 patient who underwent cesarean delivery.

32232 patients who underwent vaginal delivery and 37 patients who underwent cesarean delivery

323 did not provide estimates for blood loss at delivery. 
Table 1. Maternal Characteristics

\begin{tabular}{|c|c|c|c|c|}
\hline & $\begin{array}{l}\text { All Deliveries } \\
(\mathbf{n}=100)\end{array}$ & $\begin{array}{l}\text { Vaginal } \\
\text { Deliveries } \\
(n=49)\end{array}$ & $\begin{array}{l}\text { Cesarean } \\
\text { Deliveries } \\
(n=51)\end{array}$ & P value \\
\hline Maternal age (y) & $33(6)$ & $30(5)$ & $36(6)$ & $<0.001$ \\
\hline Race / Ethnicity: & & & & 0.54 \\
\hline Caucasian & $51(51.0 \%)$ & $27(55.1 \%)$ & $24(47.1 \%)$ & \\
\hline Asian & $32(32.0 \%)$ & $14(28.6 \%)$ & $18(35.3 \%)$ & \\
\hline $\begin{array}{l}\text { African- } \\
\text { American }\end{array}$ & $2(2.0 \%)$ & $0(0.0 \%)$ & $2(3.9 \%)$ & \\
\hline Other & $15(15.0 \%)$ & $8(16.3 \%)$ & $7(13.7 \%)$ & \\
\hline Insurance type: & & & & 0.08 \\
\hline Private & $81(81.0 \%)$ & $36(73.5 \%)$ & $45(88.2 \%)$ & \\
\hline Public & $19(19.0 \%)$ & $13(26.5 \%)$ & $6(11.8 \%)$ & \\
\hline Parity & $1[0-1]$ & $0[0-1]$ & $1[0-1]$ & 0.03 \\
\hline $\begin{array}{l}\text { Highest level of } \\
\text { education: }\end{array}$ & & & & 0.61 \\
\hline $\begin{array}{l}\text { Less than } \\
\text { college }\end{array}$ & $23(23.0 \%)$ & $13(26.5 \%)$ & $10(19.6 \%)$ & \\
\hline College degree & $26(26.0 \%)$ & $11(22.4 \%)$ & $15(29.4 \%)$ & \\
\hline $\begin{array}{l}\text { Graduate } \\
\text { degree }\end{array}$ & $51(51.0 \%)$ & $25(51.0 \%)$ & $26(51.0 \%)$ & \\
\hline $\begin{array}{l}\text { Annual } \\
\text { household } \\
\text { income: }\end{array}$ & & & & 0.45 \\
\hline $\begin{array}{l}\text { Less than } \\
\$ 10,000\end{array}$ & $2(2.0 \%)$ & $2(4.1 \%)$ & $0(0.0 \%)$ & \\
\hline $\begin{array}{l}\text { Between } \\
\$ 10,000 \text { - } \\
\$ 49,000\end{array}$ & $19(19.0 \%)$ & $10(20.4 \%)$ & $9(17.6 \%)$ & \\
\hline $\begin{array}{l}\text { Equal to or } \\
\text { greater than } \\
\$ 50,000\end{array}$ & $75(75.0 \%)$ & $35(71.4 \%)$ & $40(78.4 \%)$ & \\
\hline
\end{tabular}




\begin{tabular}{|c|c|c|c|c|}
\hline Missing & $4(4.0 \%)$ & $2(4.1 \%)$ & $2(3.9 \%)$ & \\
\hline Marital status: & & & & 1.00 \\
\hline Married & $91(91.0 \%)$ & $45(91.8 \%)$ & $46(90.2 \%)$ & \\
\hline $\begin{array}{l}\text { Unmarried - } \\
\text { lives with other } \\
\text { adults }\end{array}$ & $7(7.0 \%)$ & $3(6.1 \%)$ & $4(7.8 \%)$ & \\
\hline $\begin{array}{l}\text { Unmarried - } \\
\text { lives without } \\
\text { other adults }\end{array}$ & $1(1.0 \%)$ & $0(0.0 \%)$ & $1(2.0 \%)$ & \\
\hline Unknown & $1(1.0 \%)$ & $1(2.0 \%)$ & $0(0.0 \%)$ & \\
\hline $\begin{array}{l}\text { Gestational age } \\
\text { at delivery } \\
\text { (weeks) }\end{array}$ & 39 [38-39] & $39[38-40]$ & 39 [37-39] & 0.02 \\
\hline $\begin{array}{l}\text { Prior cesarean } \\
\text { delivery }\end{array}$ & $30(30.0 \%)$ & $2(4.1 \%)^{\mathrm{a}}$ & $28(54.9 \%)$ & $<0.001$ \\
\hline $\begin{array}{l}\text { Multiple } \\
\text { gestation: }\end{array}$ & & & & 1.00 \\
\hline Singleton & $97(97.0 \%)$ & $48(98.0 \%)$ & $49(96.1 \%)$ & \\
\hline $\begin{array}{l}\text { Twins or } \\
\text { higher-order }\end{array}$ & $3(3.0 \%)$ & $1(2.0 \%)$ & $2(3.9 \%)$ & \\
\hline $\begin{array}{l}\text { Known history of } \\
\text { anemia or } \\
\text { coagulation } \\
\text { disorder }\end{array}$ & $6(6.0 \%)$ & $4(8.2 \%)$ & $2(3.9 \%)$ & 0.43 \\
\hline
\end{tabular}

${ }^{a}$ Missing data for 1 patient 
334 Table 2. Survey of Patients' Knowledge of Normal Blood Loss for an Uncomplicated 335 Vaginal and Cesarean Delivery

336

\begin{tabular}{|l|l|l|l|l|}
\hline & $\begin{array}{l}\text { All Deliveries } \\
\mathbf{( n = 1 0 0 )}\end{array}$ & $\begin{array}{l}\text { Vaginal } \\
\text { Deliveries } \\
\mathbf{( n = 4 9 )}\end{array}$ & $\begin{array}{l}\text { Cesarean } \\
\text { Deliveries } \\
\mathbf{( n = 5 1 )}\end{array}$ & P value \\
\hline $\begin{array}{l}\text { What is the } \\
\text { normal blood } \\
\text { loss after a } \\
\text { vaginal } \\
\text { delivery? }\end{array}$ & $350[350-500]^{\mathrm{a}}$ & $350[350-500]$ & $350[350-500]$ & 0.70 \\
\hline $\begin{array}{l}\text { What is the } \\
\text { normal blood } \\
\text { loss after a CD? }\end{array}$ & $750[500-750]^{\mathrm{b}}$ & $750[350-750]$ & $750[500-750]$ & 0.66 \\
\hline
\end{tabular}

Data presented as median [interquartile range] and n (\%)

$\mathrm{CD}=$ cesarean delivery; $\mathrm{EBL}=$ estimated blood loss.

339

a 39 patients for vaginal delivery and 34 patients for cesarean delivery did not know or chose not to answer this question.

341 b 44 patients for vaginal delivery and 32 patients for cesarean delivery did not know or chose not to answer this 342 question. 
Table 3. Survey of Patients' Knowledge of Transfusion and Hemoglobin Values

\begin{tabular}{|c|c|c|c|c|}
\hline & $\begin{array}{l}\text { All Deliveries } \\
(\mathbf{n}=100)\end{array}$ & $\begin{array}{l}\text { Vaginal } \\
\text { Deliveries } \\
(n=49)\end{array}$ & $\begin{array}{l}\text { Cesarean } \\
\text { Deliveries (n=51) }\end{array}$ & P value \\
\hline $\begin{array}{l}\text { What was the } \\
\text { quality of } \\
\text { information you } \\
\text { received about } \\
\text { blood transfusion? }\end{array}$ & & & & 0.04 \\
\hline $\begin{array}{l}\text { Clear and } \\
\text { understandable }\end{array}$ & $32(32.0 \%)$ & $10(20.4 \%)$ & $22(43.1 \%)$ & \\
\hline $\begin{array}{l}\text { Incompletely } \\
\text { explained but I } \\
\text { have a good } \\
\text { understanding }\end{array}$ & $41(41.0 \%)$ & $20(40.8 \%)$ & $21(41.2 \%)$ & \\
\hline $\begin{array}{l}\text { Poorly } \\
\text { explained and I } \\
\text { have limited } \\
\text { understanding }\end{array}$ & $10(10.0 \%)$ & $6(12.2 \%)$ & $4(7.8 \%)$ & \\
\hline $\begin{array}{l}\text { Not explained } \\
\text { and I have no } \\
\text { understanding }\end{array}$ & $13(13.0 \%)$ & $10(20.4 \%)$ & $3(5.9 \%)$ & \\
\hline Missing & $4(4.0 \%)$ & $3(6.1 \%)$ & $1(2.0 \%)$ & \\
\hline $\begin{array}{l}\text { If a blood } \\
\text { transfusion was } \\
\text { needed, would you } \\
\text { give consent? }\end{array}$ & & & & 0.09 \\
\hline Yes & $85(85.0 \%)$ & $38(77.6 \%)$ & $47(92.2 \%)$ & \\
\hline No & $14(14.0 \%)$ & $10(20.4 \%)$ & $4(7.8 \%)$ & \\
\hline Missing & $1(1.0 \%)$ & $1(2.0 \%)$ & 0 & \\
\hline $\begin{array}{l}\text { Were you given } \\
\text { any information } \\
\text { about your } \mathrm{Hb}\end{array}$ & & & & 0.02 \\
\hline
\end{tabular}




\begin{tabular}{|c|l|l|l|l|}
\hline $\begin{array}{l}\text { level before your } \\
\text { delivery? }\end{array}$ & & & & \\
\hline Yes & $39(39.0 \%)$ & $24(49.0 \%)$ & $15(29.4 \%)$ & \\
\hline No & $57(57.0 \%)$ & $25(51.0 \%)$ & $32(62.8 \%)$ & \\
\hline Missing & $4(4.0 \%)$ & $0(0.0 \%)$ & $4(7.8 \%)$ & \\
\hline $\begin{array}{l}\text { Was your Hb level } \\
\text { measured after } \\
\text { delivery? }\end{array}$ & $44(44.0 \%)$ & $20(40.8 \%)$ & $24(47.0 \%)$ & 0.74 \\
\hline Yes & $33(33.0 \%)$ & $18(36.7 \%)$ & $15(29.4 \%)$ & \\
\hline No & $22(22.0 \%)$ & $11(22.4 \%)$ & $11(21.6 \%)$ & \\
\hline Don't know & $1(1.0 \%)$ & 0 & $1(2.0 \%)$ & \\
\hline Missing & & & & \\
\hline
\end{tabular}

Data presented as n (\%)

$348 \mathrm{Hb}=$ hemoglobin.

349

350 